\title{
EVOLUTION OF THE CONCEPT OF VALUE AND CLASSIFICATIONS OF HERITAGE VALUE
}

\author{
Marwa Sayed Mohammed Mohammed ${ }^{*}$ and Amr Mostafa Kamal Al-Halfawi ${ }^{2}$ \\ ${ }^{1}$ Architectural Engineering Department, Faculty of Engineering, 6th of October \\ University, Cairo, Egypt. \\ ${ }^{2}$ Architectural Engineering Department, Faculty of Engineering, Cairo University, \\ Cairo, Egypt. \\ *Corresponding Author E-mail: eng_marwaphd@yahoo.com
}

\begin{abstract}
:
The research reviews the concept of value for sociologists and philosophers, and studies the relationship of value to architectural heritage according to Cullen's classification, explaining the difference between historical buildings and buildings of visual and related value, and then reviews the values according to the classification of Worsket (historical value - architectural value - economic value - architectural value - value Political .....) and the concept of each. The research also clarifies the three main axes of values according to the local classification and the indicators affecting each axis, and the guidelines for Egyptian Law No. 109 (for the year 2008) and the Civilization Coordination Manual issued by the National Authority for Urban Harmony (NOUH). The research aims to compare the classifications of values previously presented through matrix Analyzing cultural values according to four global and local classifications, analyzing them and presenting a new classification of heritage values.

The research tried to reach a new classification of the value by which the buildings of heritage value can be classified, to determine the best way to deal with them.
\end{abstract}

\section{KEYWORDS: Value, Architectural Heritage, Classifications of Value, Indicators of Value, and Value Matrix.}

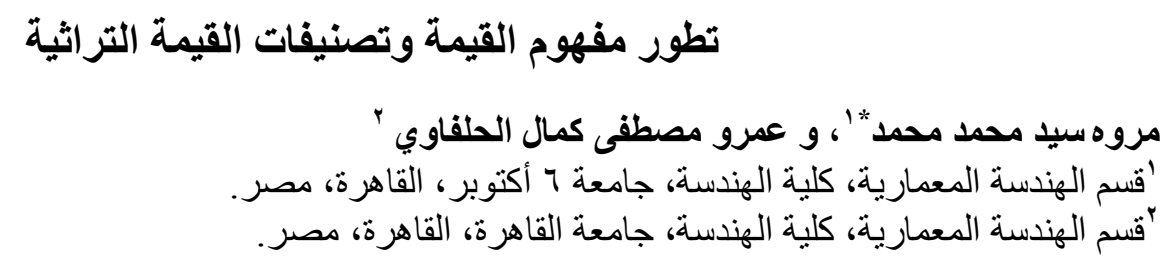

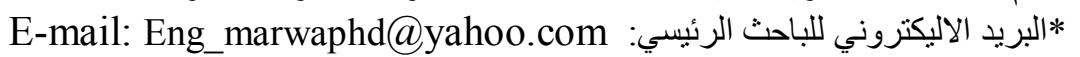

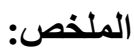

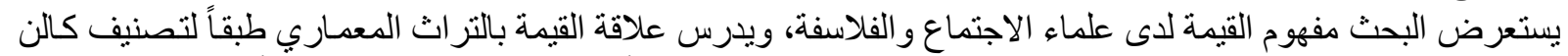

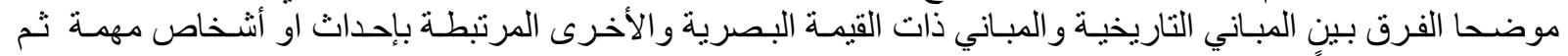

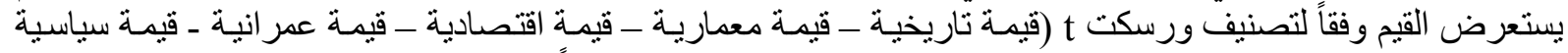

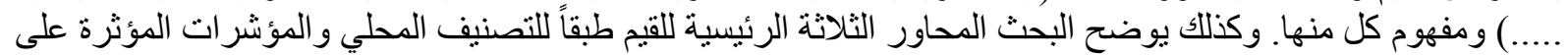

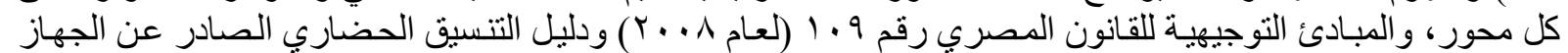




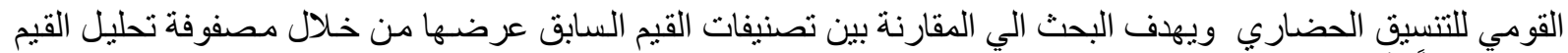

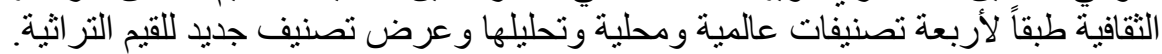

ولقد تم تطوير مجموعة متنوعة من أساليب التقبيم على مدار العقود الأخيرة ويعتبر مبدأ التقييم من المبادئ لإئ الأساسية

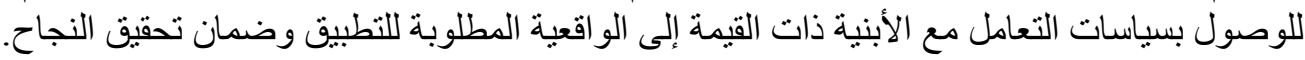

وقد حاول البحث الوصـول إلى تصنيف جديد للقيمة يمكن من خلالهه تصنيف المباني ذات القيمـة التراثيـة لإمكانية تحديد الأسلوب الأمثل للتعامل معها.

الكلمات المفتاحية: القيمة، التراث المعماري، تصنيفات القيمة، مؤشرات القيمة، ومصفوفة القيمة.

المقدمة: مشكلة البحث، هاف البحث، منهجية البحث

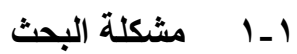

تتمثل مشكلة البحث في تعدد تصنيفات القيمة التراثية وتداخلها والتي تحدد على إثر ها استر اتيجيات رعاية وصئ وصيانة النسيج

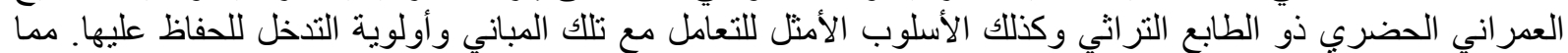

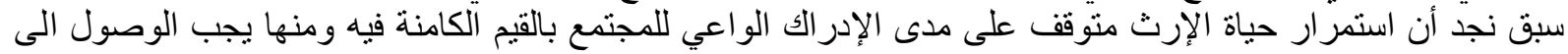

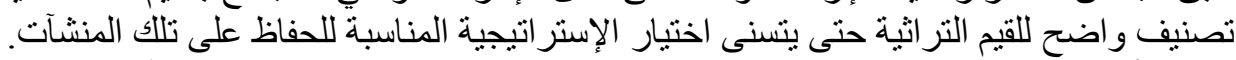

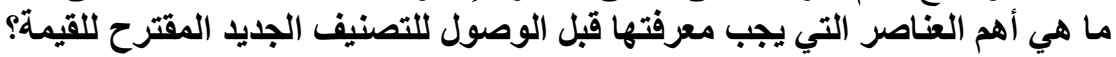

للإجابة على هذا السؤ ال لابد أو لاً من التوصل لإنها لإجابات على الأسئلة الثانوية الآتية:

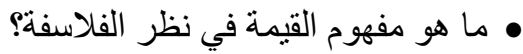

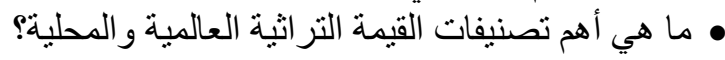

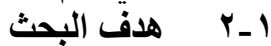

ان الهدف الرئيسي للار اسة يتمثل في المقارنة بين تصنيفات القيم للوصول إلى مصفوفة تحليل القيم الثقافية طبقاً لأربعة تصنيفات عالمية ومحلية وتحليلها، في محاولة الوصول إلى تصنيف جديد للقيم التراثية هذا بجانب بعض الأهداف الفر عية لألية

• م استعر اض مفاهيم القيمة و علاقتها بالتراث المعماري.

• وصف وتحليل اهم تصنيفات القيم الثقافية العالمية و المحلية.

• إستنتاج و تحليل مصفوفة القيم التر اثية.

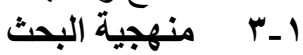

للوصول إلى الهذف الرئيسي للبحث؛ فأن الدراسة تعتمد على الخطو ات البحثية التالية:

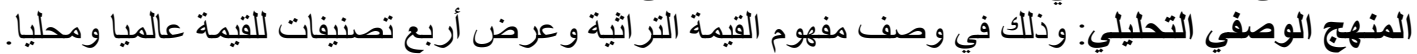
المنهج الاستتتاجي: وذللك في استتناج مصفوفة القيم التراثية وتحليلها والخروج التئية منها بتصنيف جديد للقيمة التراثية يساعد

في اختيار استر اتيجيات الحفاظ المناسبة للتعامل مع كل مبنى.

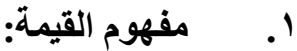

أولاً: تعريف القيمة

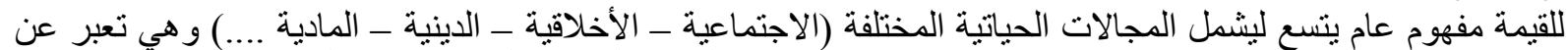

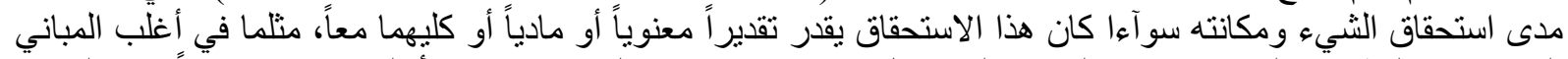

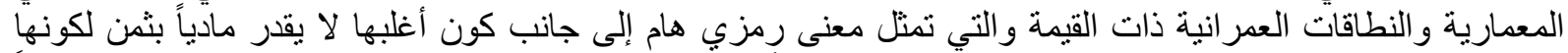

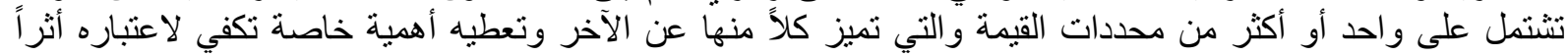
واجب الحماية. كلمة قيمة value مشتقة من الفعل اللاتيني Valeo ومعناها أنا قوب أو غني بصحة جيدة، و يطلق لفظ قيمة اصطلاحا على

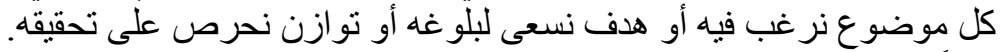

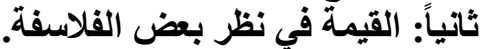

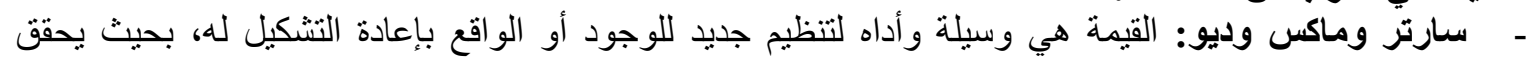

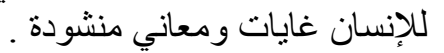

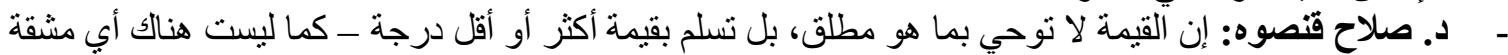

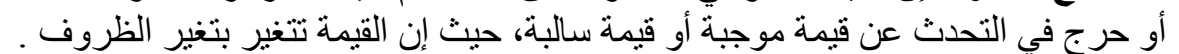

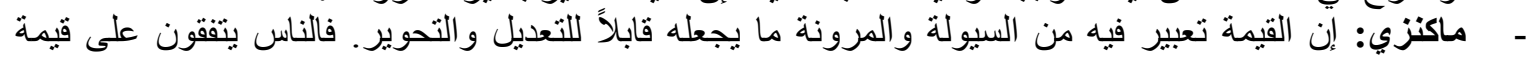

بعينها ولكنهم يختلفون على مدى انطباعهم على هذا الثيء الثيء أو ذاك. 


\section{تطور مفهوم القيمة وتصنيفات القيمة التراثية}

- تصنيف علماء الاجتماع: بقترح فريق من علماء الاجتماع تصنيفا للقيم على أساس الثنكل و المحتوى و القصد

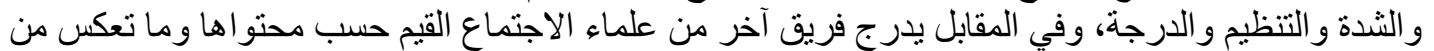

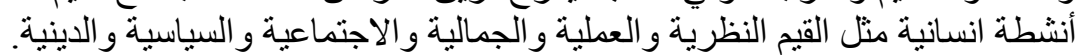

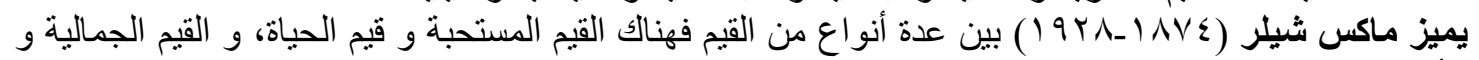
الأخلاقية و الدينية.

- - متناول القلسفة القيم من ثلاثة أبعاد هي الحق، الخير والجمال:

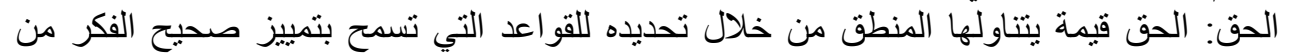

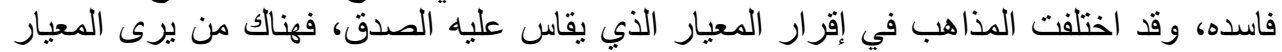

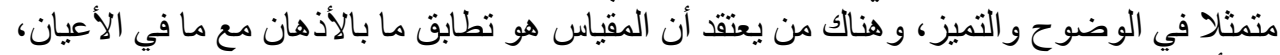
كما أن فئهم من يجعل الفيائدة العملية هي المعيار.

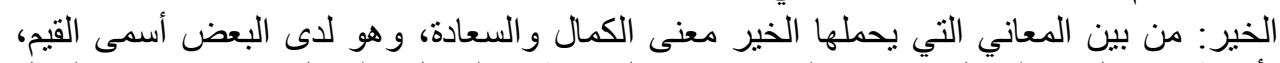

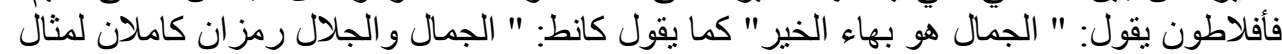

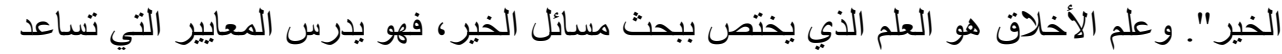
على تمييز الفعل الصائب من الخاطئ (الخير من الثر الثر ).

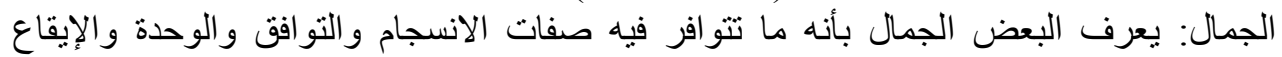

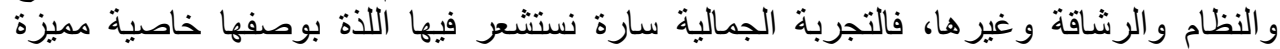

$$
\text { اللثيء نفساء. }
$$

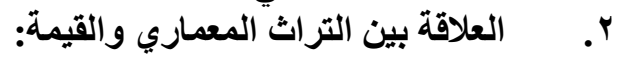

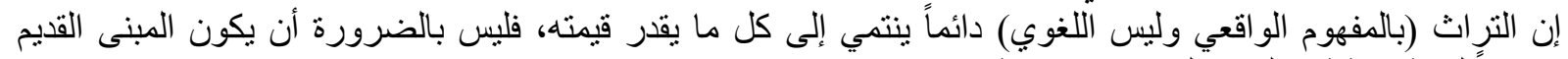

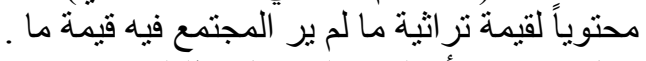

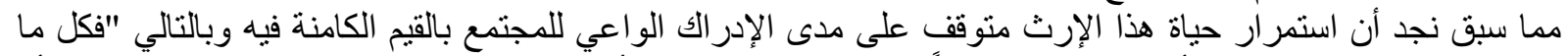

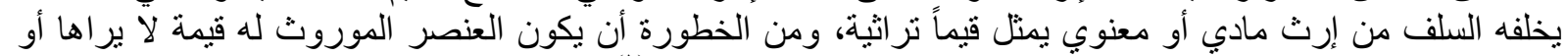

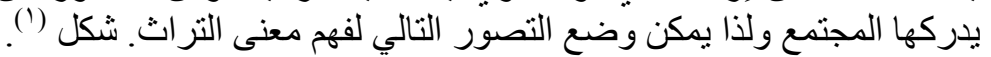

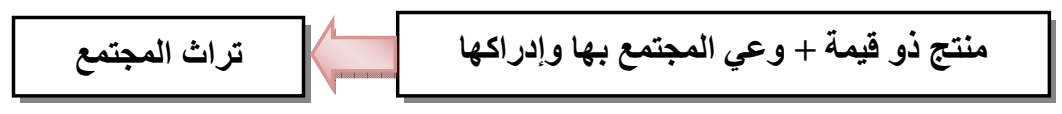

شكل (1): العلاقة بين التراث المعماري والقيمة.

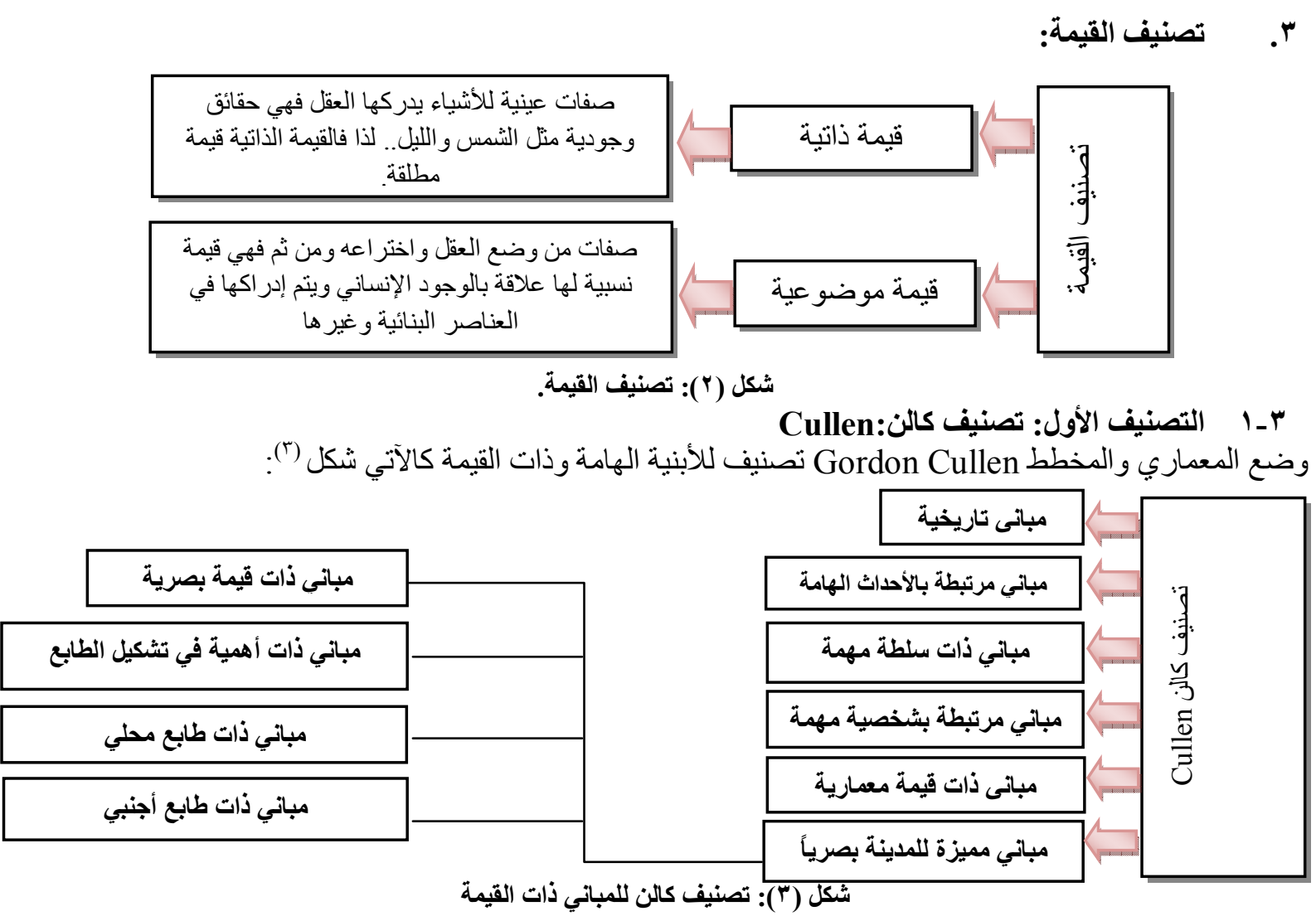




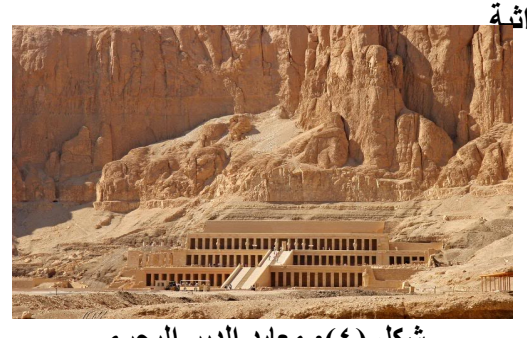

شكل (צ): معابد الدير البحري.

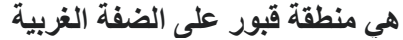
على النيل مقابلة لمدينة طيبة القيايمة (الأقصر ) ملابنة

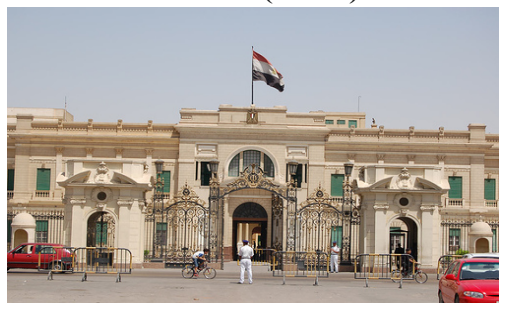

شهل (0): قصر عابلين الذي شهام إحداث مهمة منذ العصر الملكي وحتى قيام ثورة

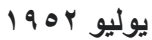

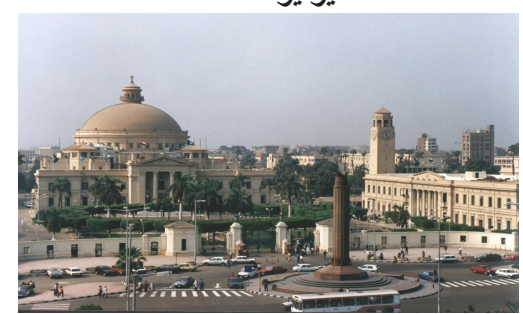

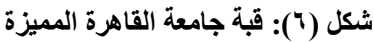
كبؤرة بصرية في الثكل والحجم العبرة

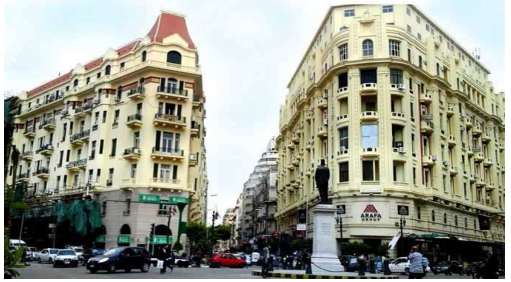

شكل (V)): عمار ات القاهرة الخديوية متناسقة من

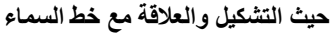

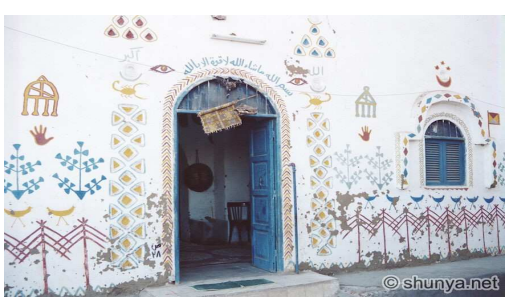

شكل (^): عمارة النوبة وتثكيلاتها

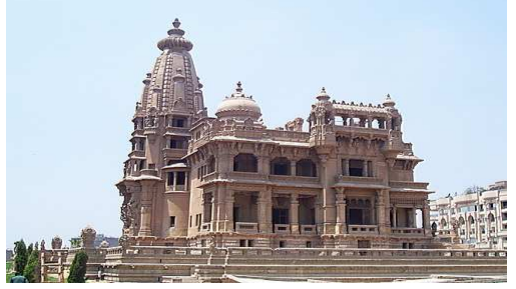

شكل (9): قصر البارون بني على النى

طراز العمارة الهندوسية الأوروبية

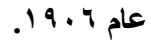

تطور مفهوم القيمة وتصنيفات القيمة التراث

تتمثل في الأبنية القديمة من العصية العصور الماضية والتي تعتبر كسجل تاريخي

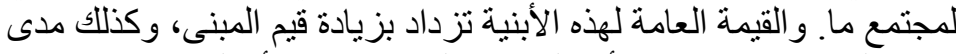

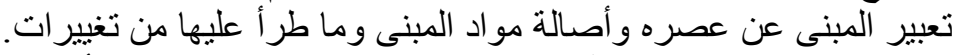

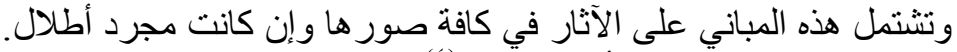

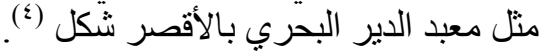

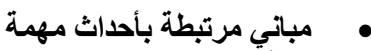

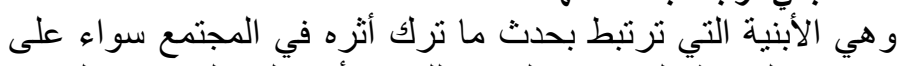

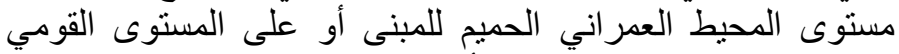

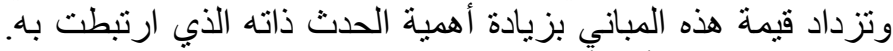

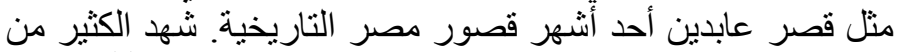

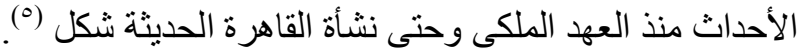

• • مباني ذات قيمة بصرية أو تثكيلية في المدينة

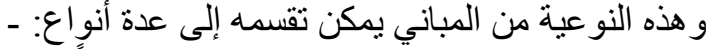

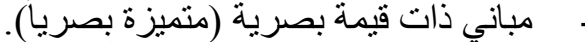
و وتشمل على المباني المتميزة لوناً أو حجماً أو في التشكيل المعمداري المئي

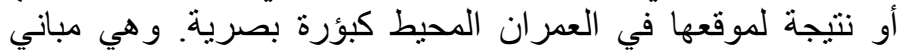

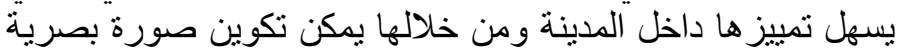

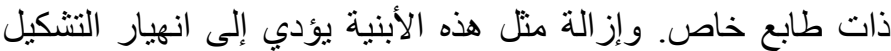

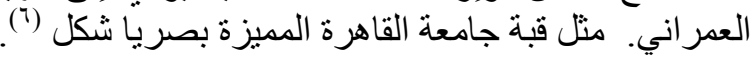

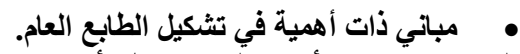

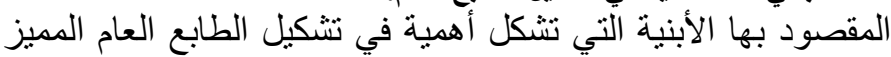

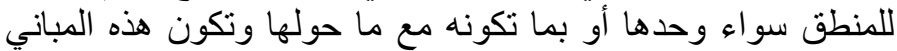

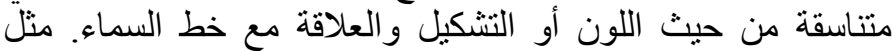

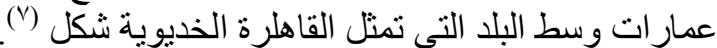
و هي تلك المباني التي تحمل سمات فن التيات المعمار المحلي بالمنطقة

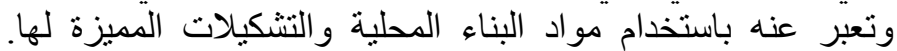

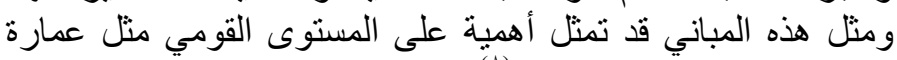

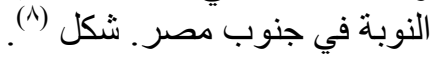

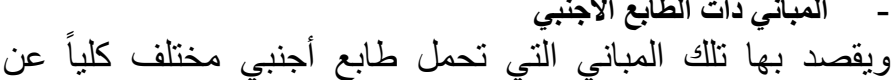

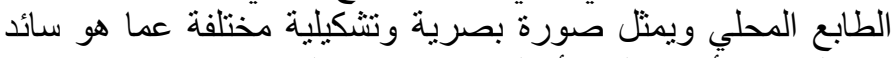

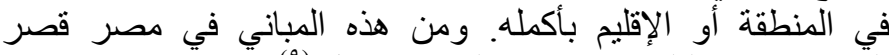
البارون إمبان البلجيكي بمصر الجديدة. شكل (9).

• مباني تعبر عن سلطة مهمة و هي مباني ترتبط قيمتها بوظيفتها، وتزداد أهميتها بأهمية السلطة الهية

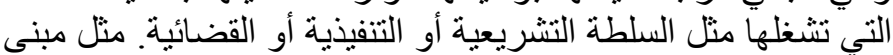

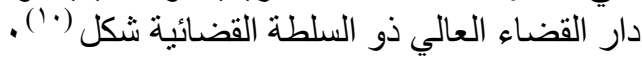

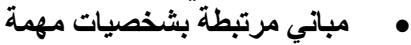

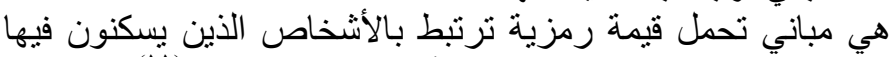

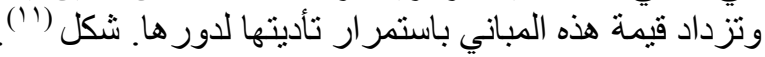


تطور مفهوم القيمة وتصنيفات القيمة التراثية

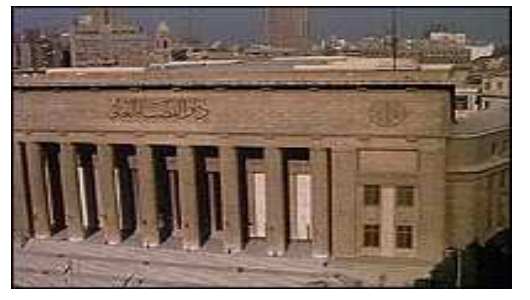

شكل (• (1): دار القضاء العالي مبنى ذو سلطة قضائية.

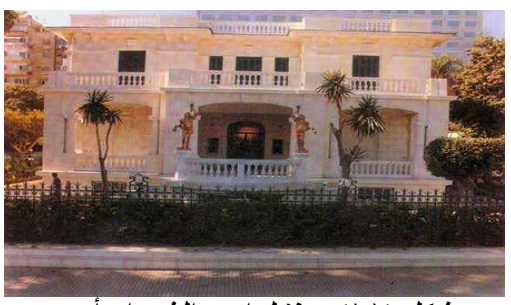

شكل (1'): منزل امير الثعراء أحمد شوقي الذي تحول الى متحف الشير

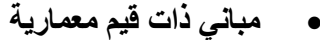 \\ وهي مباني متميزة معمارياً أو إنشائياً، تخص أخدارئ أحد المعماريين

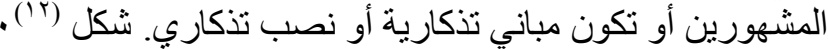

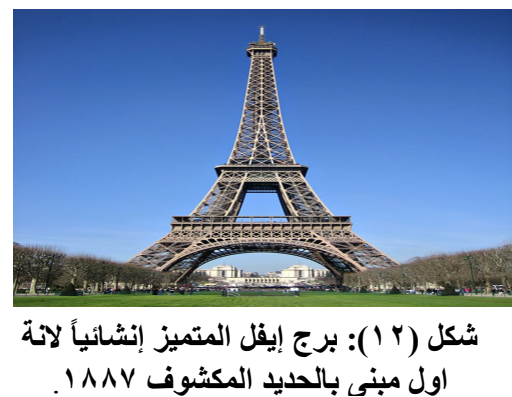

Worsket r r r r r T التصنيف الثاني: تصنيف ورسكت

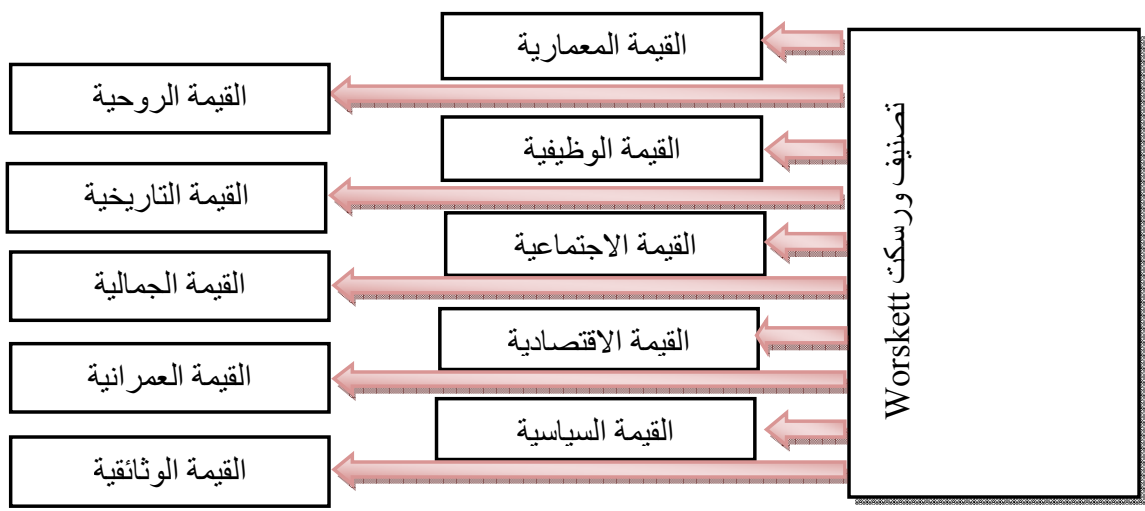

شكل (r ا ): تصنيف ورسكت للقيم التراثي

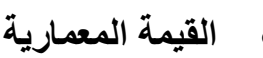

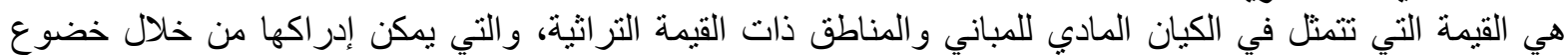

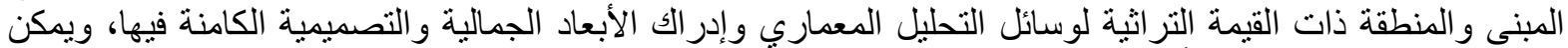

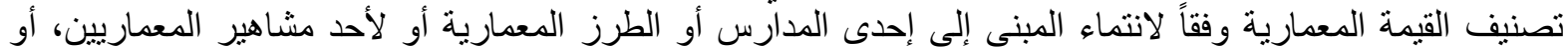

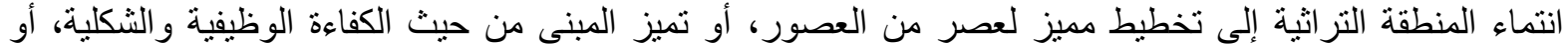

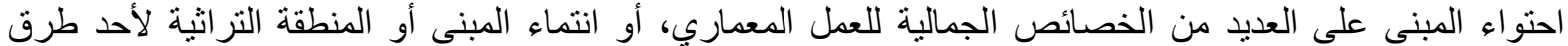

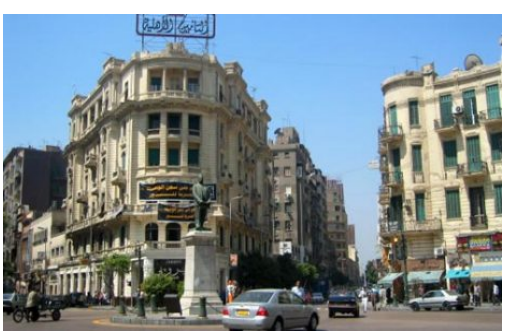

شكل (؛ (1): عمارة القاهرة الجديوية ذات التخطيط المميز

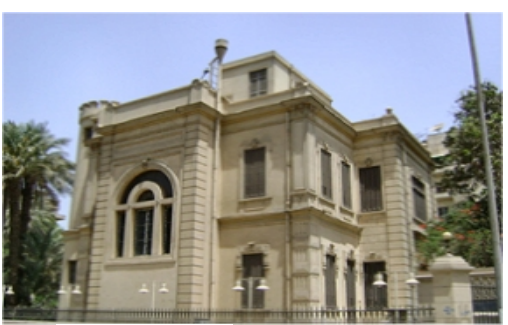

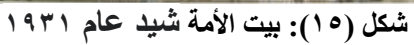

ليدفن فيه الزعيم سعد زعلول قائل الثورة

ضد الاحتلال الإنجليزي ثورة 1919

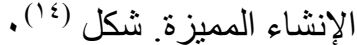

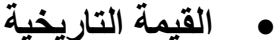

وهي القيمة النابعة من بقاء المنطقة أو المبنى لفترة زمنية طويلة شاهداً

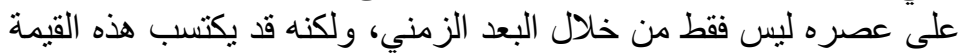

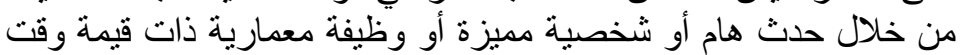
إنشائه، منل منزل سعد ز غلول شكل (10)

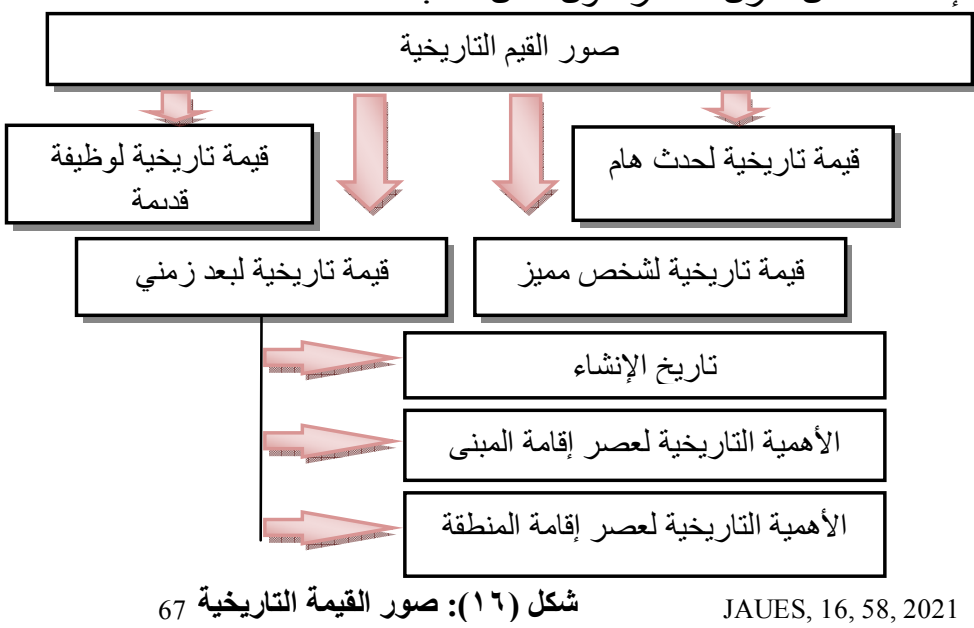



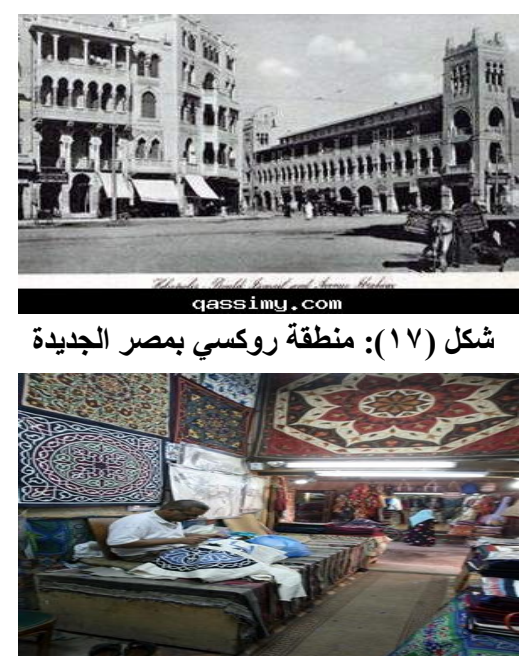

شكل (1) أ): منطقة الخيامية لصنع اقششة السر ادقات منذ عهل الفاطميين

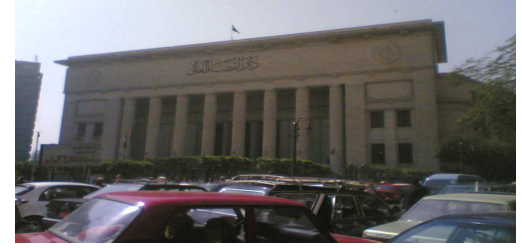

شكل (9 19): دار القضاء العالي التي ما زالت تؤدي وظيفتها التي منحتها القيمة

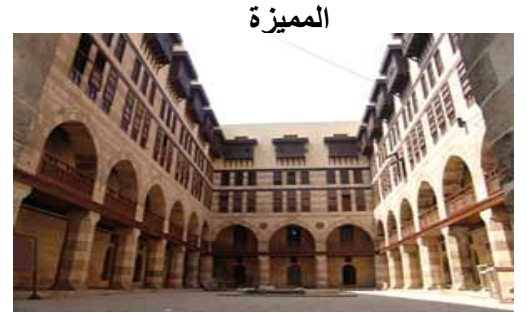

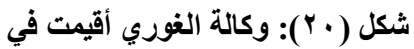

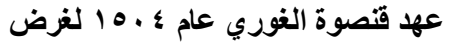

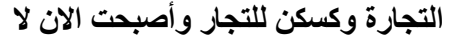
تؤدى تلك الوظيفه

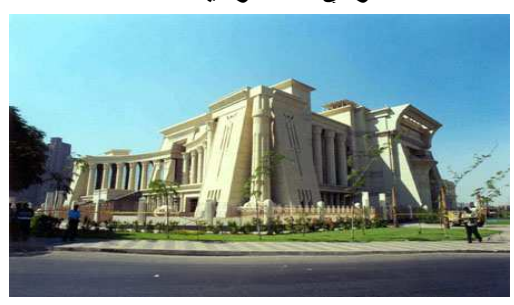

شكل (آY): مبنى المحكمة الاستورية العليا

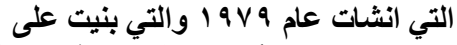
الطراز الفرعوني وأصبحت ذات قيمة جمالية

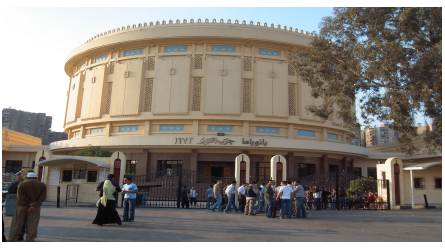

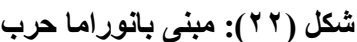

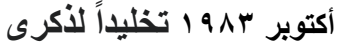
انتصار مصرفى حرب السنادي

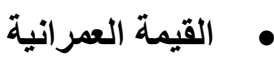

تنبع القيمة العمر انية من علاقة ترابط المبنى بالمحيط المبط العمر اني واحتلاله

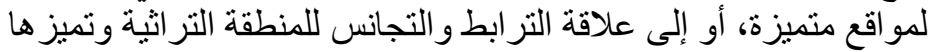
بسمات وخصائص تحدده منفردة أو مجتمعة وتتمثل فيما يلي: -

\section{- الطابع العمراني:CHARACTER}

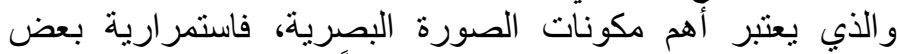

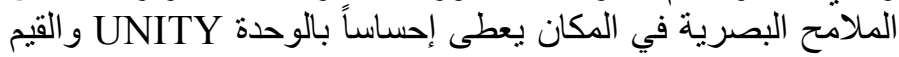

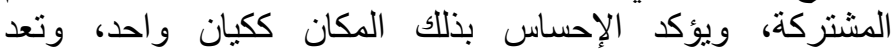

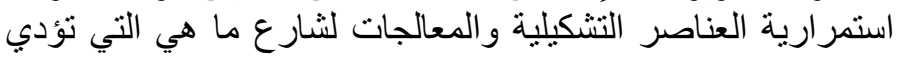

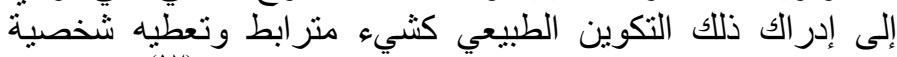

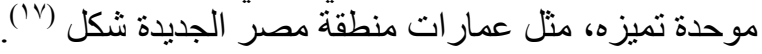

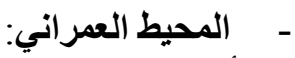

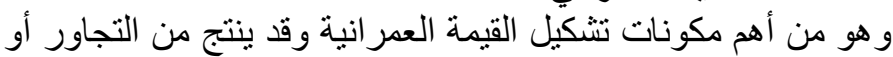
التجمع لنشاط مميز ذو قيمة في الوقت الحاضر كالأنشطة الحرفية

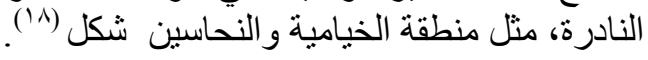

\section{• - م القيمة الوظيفية}

يرتبط تقدير القيمة الوظيفة الوبية بمدى وفاء المبنى لمتطلباته، ويمكن تقسيم المباني و المناطق ذات القيمة القيمة التراثية كالثالئي -

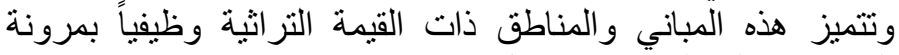

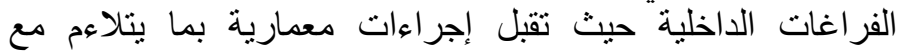
الوظيفة المستجدة دون المساس بباقي القيم التي يحتوي عليها المبنى.

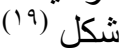

\section{- مباني و مناطق تر اثبة خاملة:}

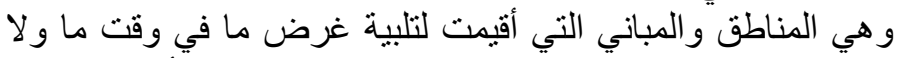

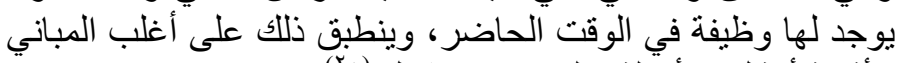

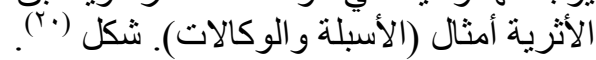

$$
\text { • القيمة الجمالية الانية }
$$

هي قيمة تتبع من خلال تلك الصورة الذهة الذهنية الحسية أو المادية النابعة

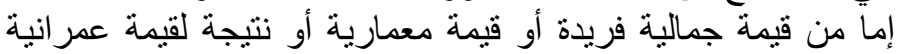

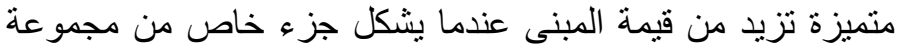

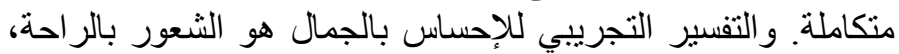

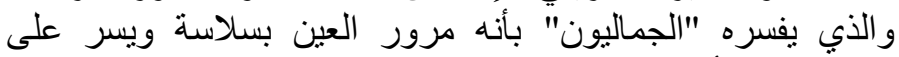

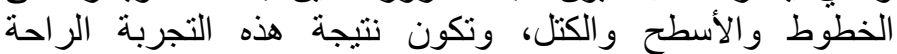
و الاستقرار في النفس البشرية مثل مبنى المحكمة الدستورية العليا،

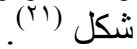

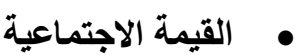

لا تتواجد هذه القيمة بكثرة إلى من خلاجل الأبنية الدينية أو بعض الأبنية، الإبها

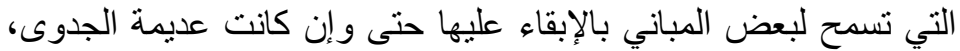

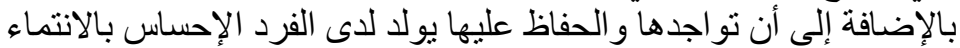

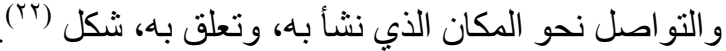




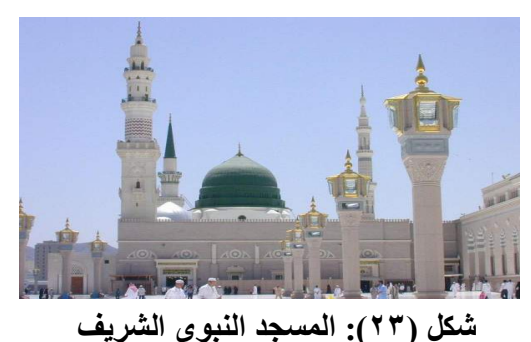

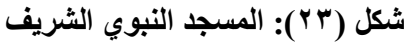

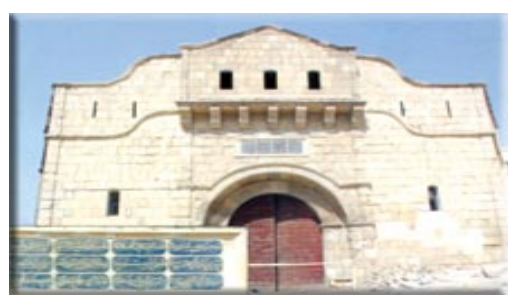

شكل (ع ץ): دار المحفوظات بالقلعة

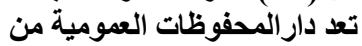
أقدم الكيانات المعنية بحفظ الوثائق الومن فئق

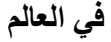

\section{• القيمة الاقتصادية}

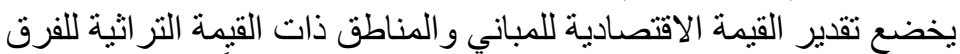

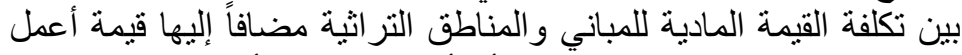

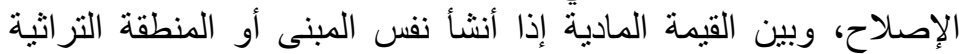

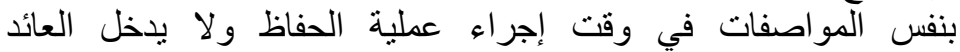
الاقتصادي في حساب القيمة الاقتصادية في كثير من مشارئ القاطيع الحفاظ. وتمنل القيمة المادية للمباني والمناطق ذات القيمة القاتية التراثية للعناصر الآتية: قيمة الأرض والمبنة المادية للمباني والعمال الحفاظ.

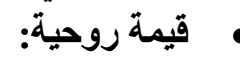

و هي المباني التي تمثل قيمة مهمة، فعلى سبيل المثال نجد أن المسجد

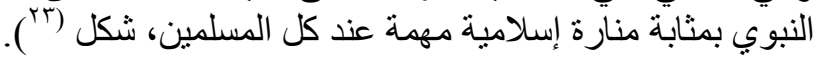

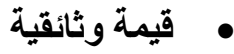
وهي ذات قيمة تنبعث من من كونه مكان لحفظ كتب التراث مثل دار

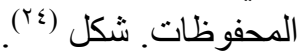

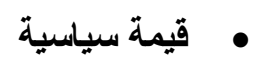

وهي المباني التي تكتسب قيمنها من خلال حدث سياسي، أو شخصية

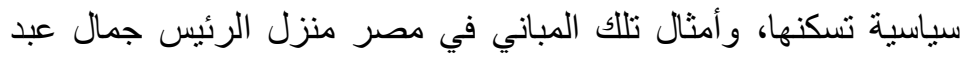

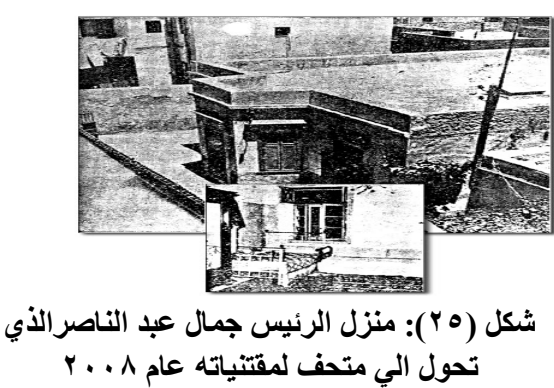

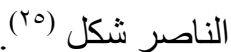
r r r r التصنيف المحلي (للمعمارين المصريين)

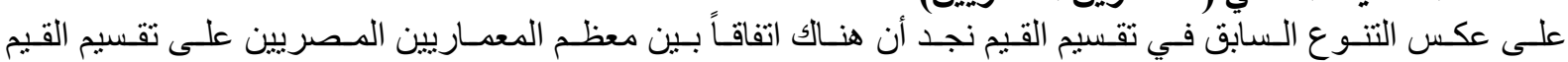

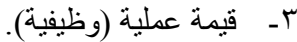

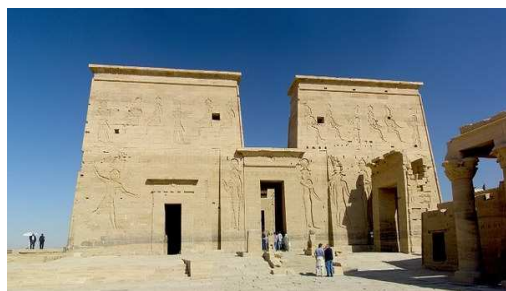

شكل († ץ): معبد فيلة أحد العابد الفرعونية الذي شيد لعبادة الاله ايزيس العابل استمد قيمته من بقاءه لفترة زمنية كبيرة

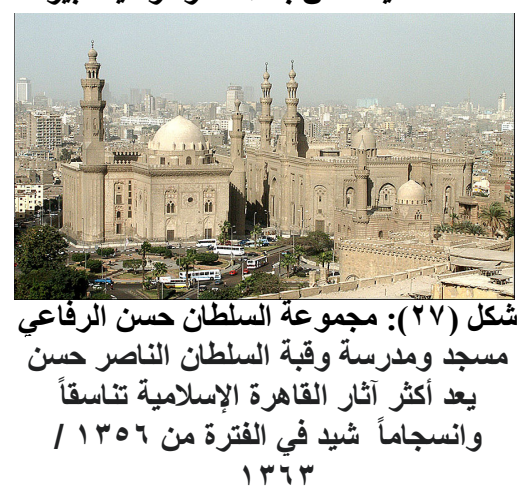

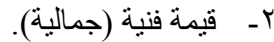
إلى ثلاث محاور رئيسية و هي:

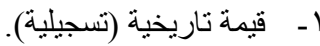

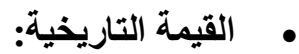

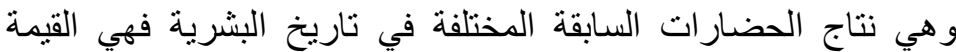

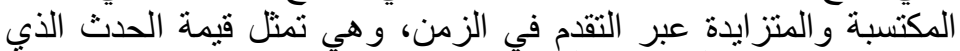

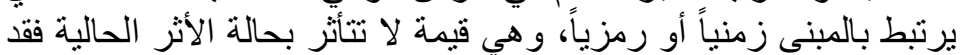

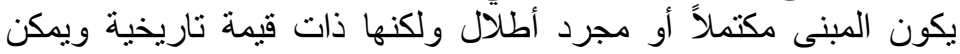
قياس القيمة التاريخية للمباني باستخدام مؤشرين أساسيين: القيمة الزمنيةً

تتوقف على استمرار حياة العمل الفني أو المحتوى المادي والقادئة الحالة العامة

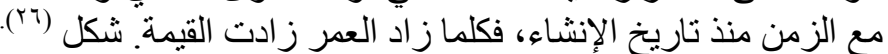

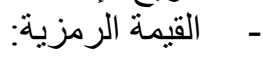

تتمنل في كون العمل الفني / المحتوى المادي (مباني / نطاقات) يعكس

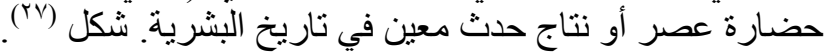

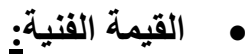

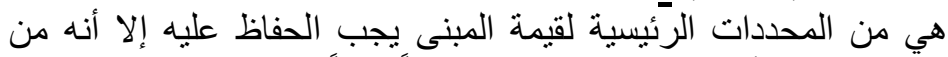

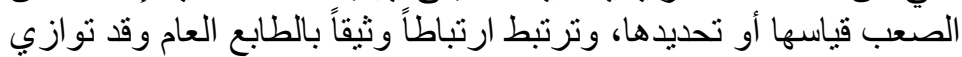

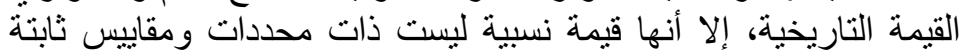


و إنما تتأثر باعتبار ات مختلفة مثل: القدرات الإنسانية، القدرات الإبداعبة، و الخروج عن المألوف. وقسمت في هذا التصنيف الى خمس مستويات:
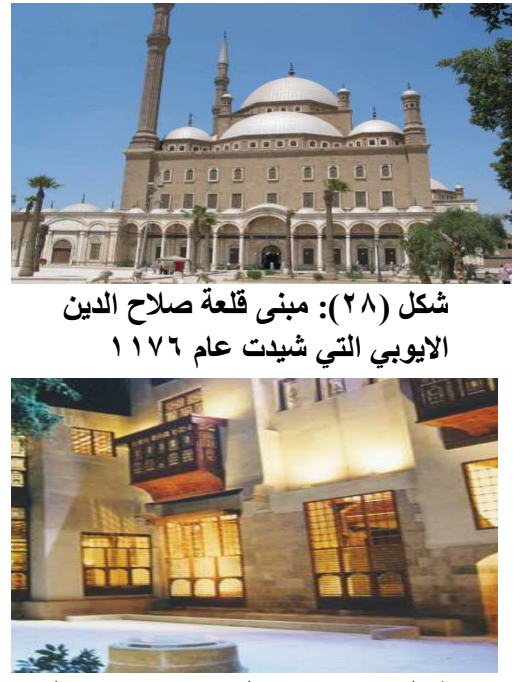

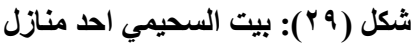

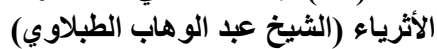

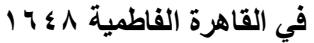

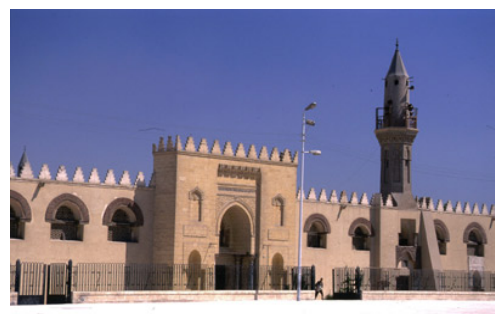

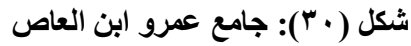

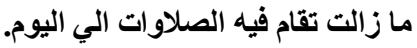

-

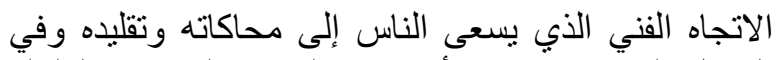

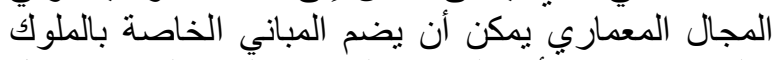

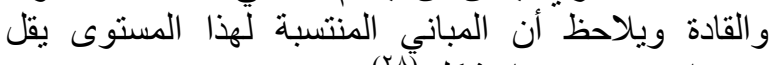

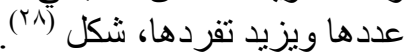

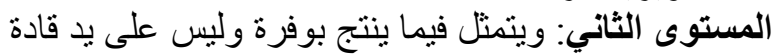

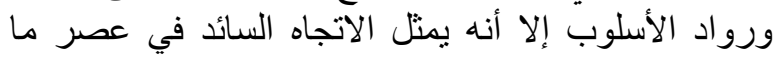

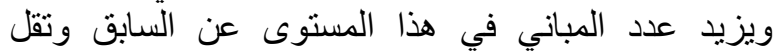
قيمتها. مثل منازل الأثرياء و المشاهير في القاهرة الفاطمية،

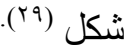
المستوى الثالث:_و هي الأبنية التي لا تمثل أسلوب أو اتجاه

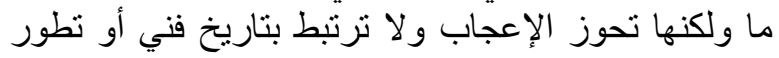

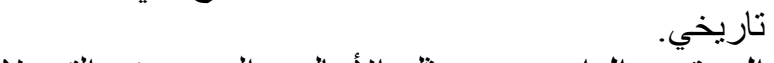
المستوى الرابع:_هو يمثل الأساليب المهجورة و التي لا لإنئل تعرف إلا بواسطة المؤرخين وتمثل الأبنية التقليدية لتحقيق التيق لإيق غرض وظيفي مؤقت. المستوى الخامس: ويمنل الأساليب الرديئة وغير الهامة وأغلب هذه النوعية من المباني لا يصمد لفترات زئن زمنية طويلة ومنسي وغير ذي قيمة.

\section{القيمة العلمية (الوظيفية أو النفعية):}

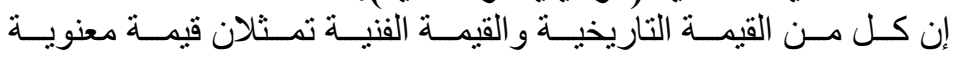

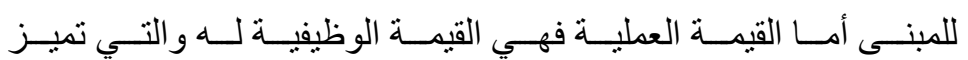
الأثر المعماري عن باقي أثار الفنون الأخرى.

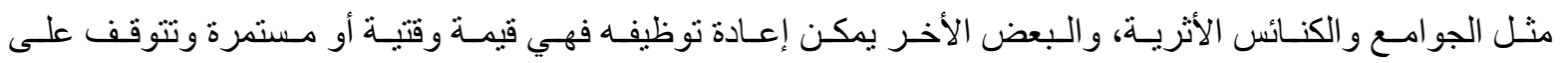

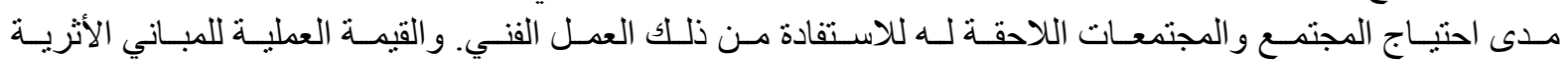

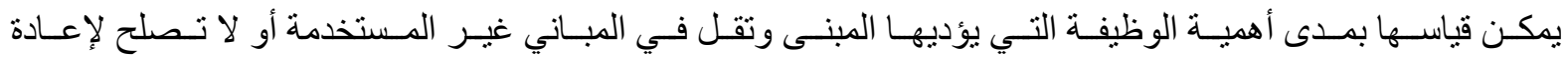

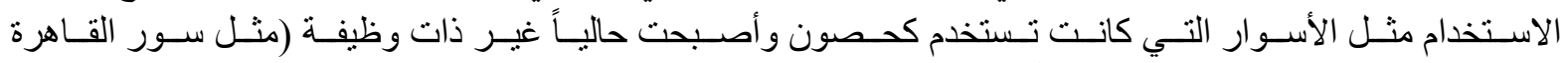

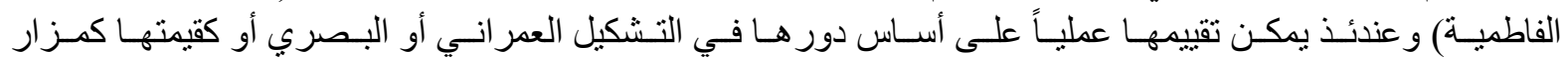

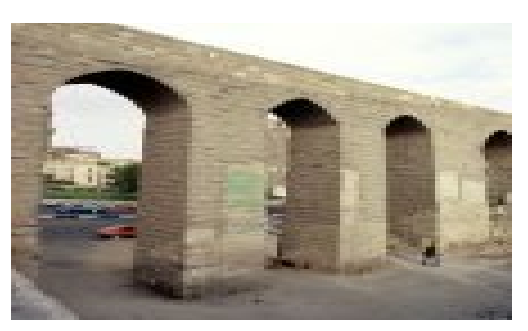

شكل ( آب): سور مجرى العيون الأي توقف عن تادية وظيفته و التي كانت توصيل المياه من النئ النيل لقلعة صلاح الدين
وبالتالي يمكن تقسيمها إلى:

\section{-}

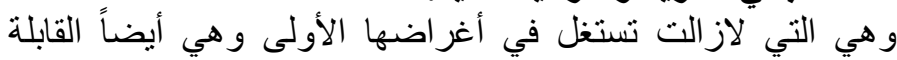

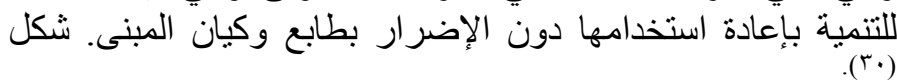

$$
\text { - }
$$

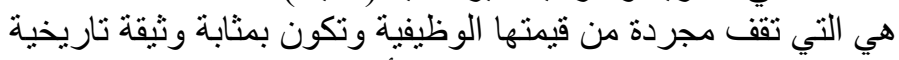

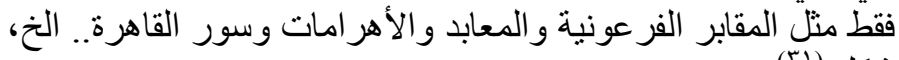




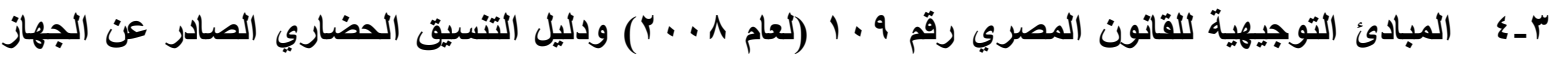

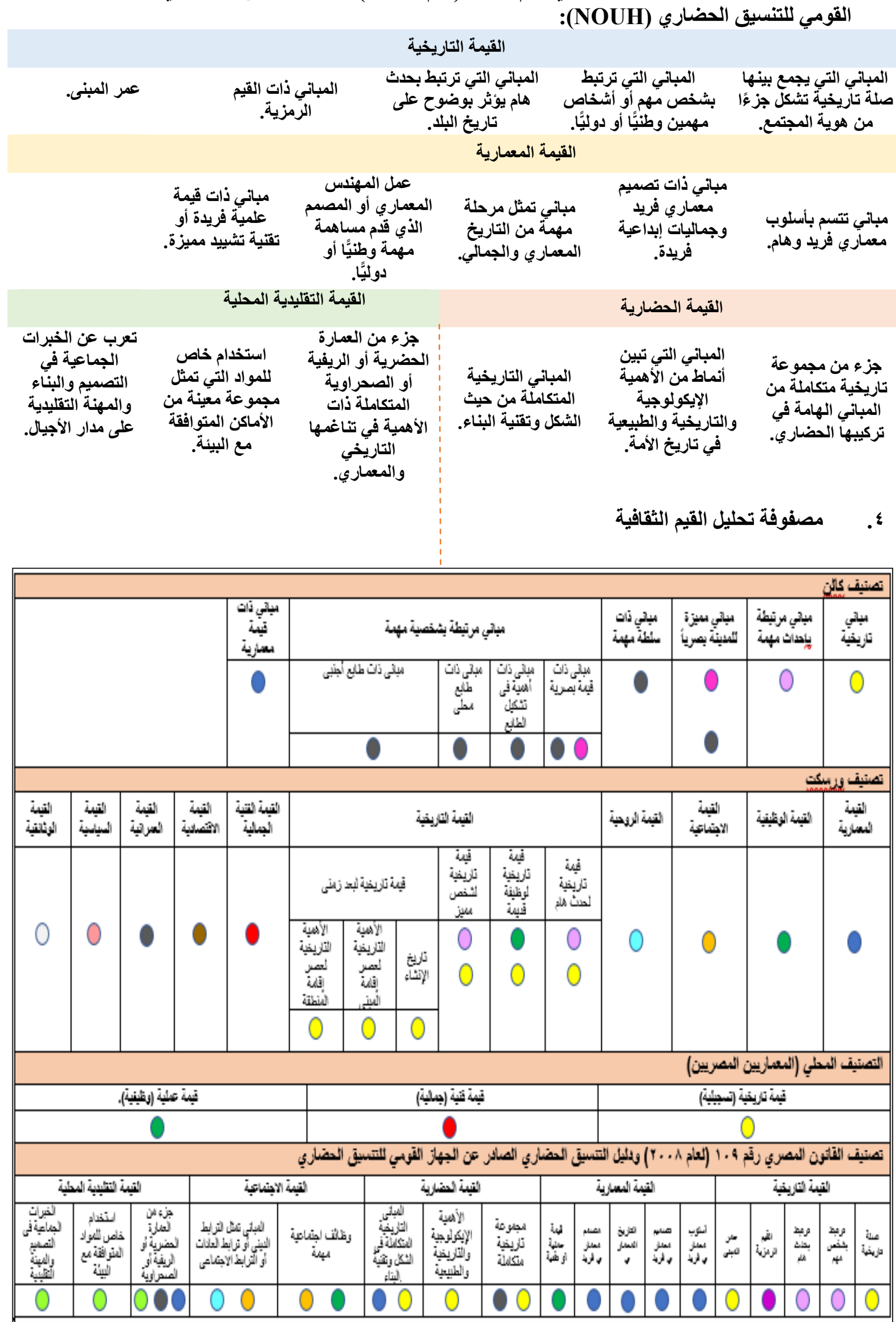

شكل (rץ): مصفوفة تحليل القيم الثقافية طبقاً لأربعة تصنيفات عالمية ومحلية 
ه. ت ملال عزليل مصفوفة القيمة

كن خلال عرض مصفوفة القيمة التي تجمع بين تصنيفات القيمة المختلفة يمكننا استخلاص تصنيف جديد من ذلك التحليل كالاتي:

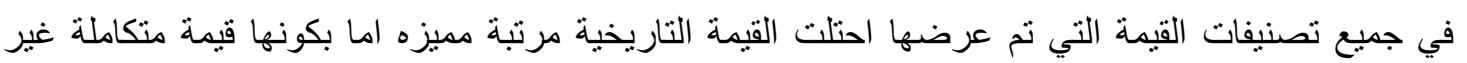
مجز أه أو بصور ها المختلفة للحدث أو الوظيفة أو الأشخاص أو أو كونها قيمة تسجية الفيلية.

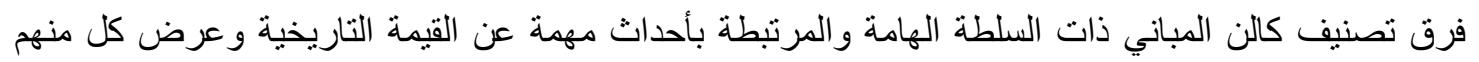

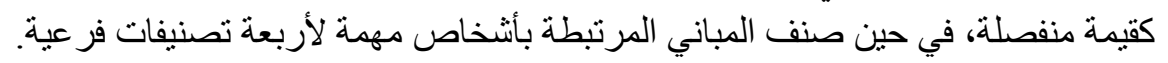

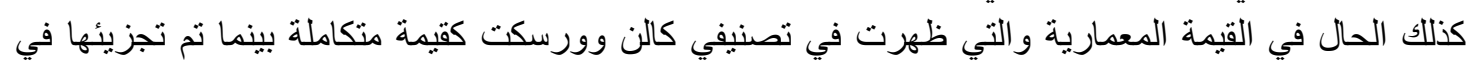

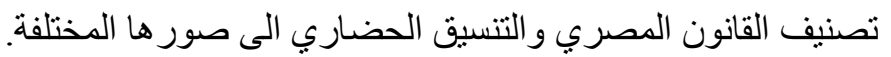

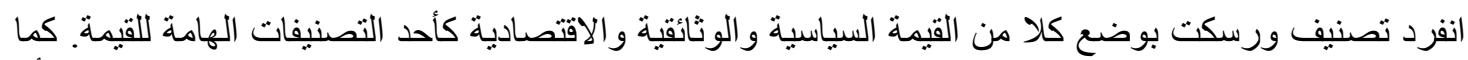

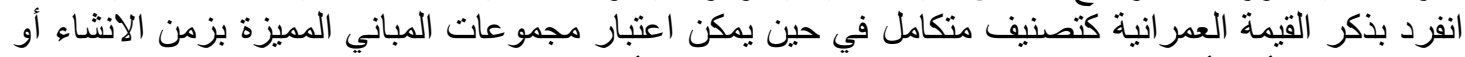

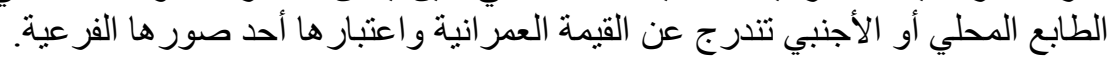

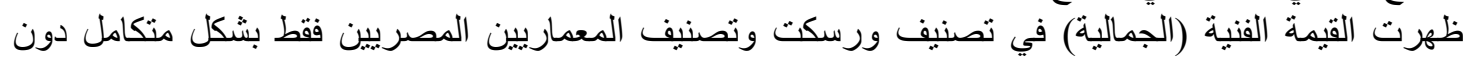
تجزيئها لقيم فرعية في التصنيفين. كما ظهرت القيمة الوظيفية بهذا المسمى في تصنيف ورئيف ورسكت كقيمة متكاملة، وذكرت في تصنيف القانون

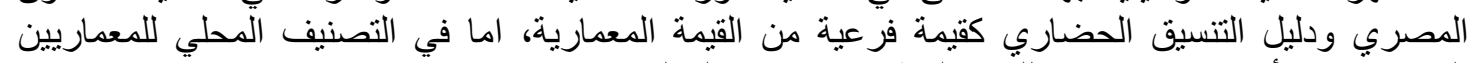

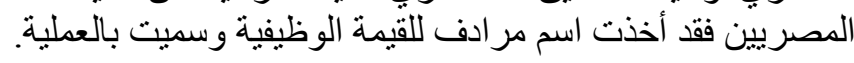

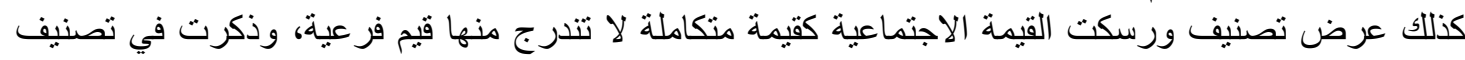

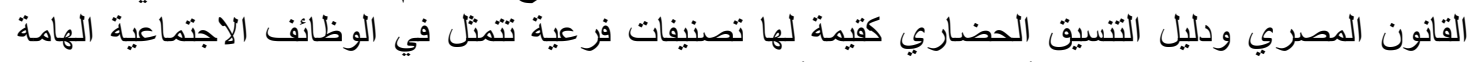

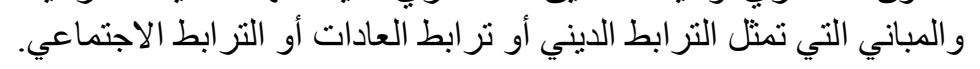

انفرد تصنيف ورسكت بذكر القيمة الروحية كقيمة متكاملة في تصنيفات القيم الهامة لديه ولم يتم ذكر ها نهائيا في

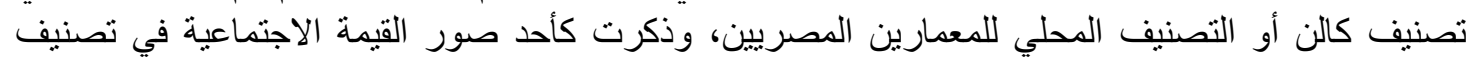
القانون المصري ودليل التنسيق الحضاري تحت مسمى المباني التي تمثل التر ابط الديني.

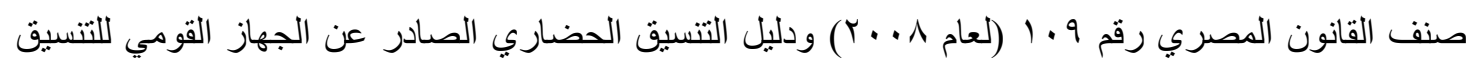

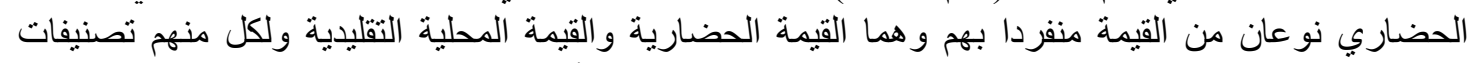

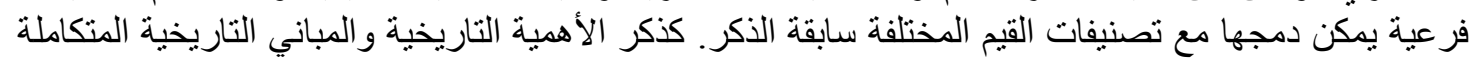

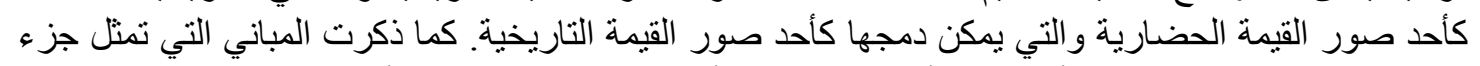

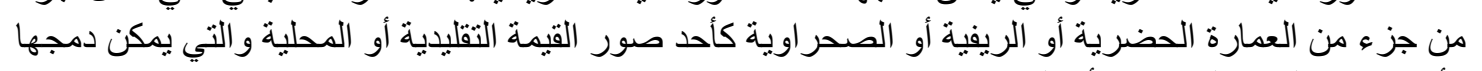
كأحد صور القيمة المعمارية أو العمر انية. 
التصنيف المقترح
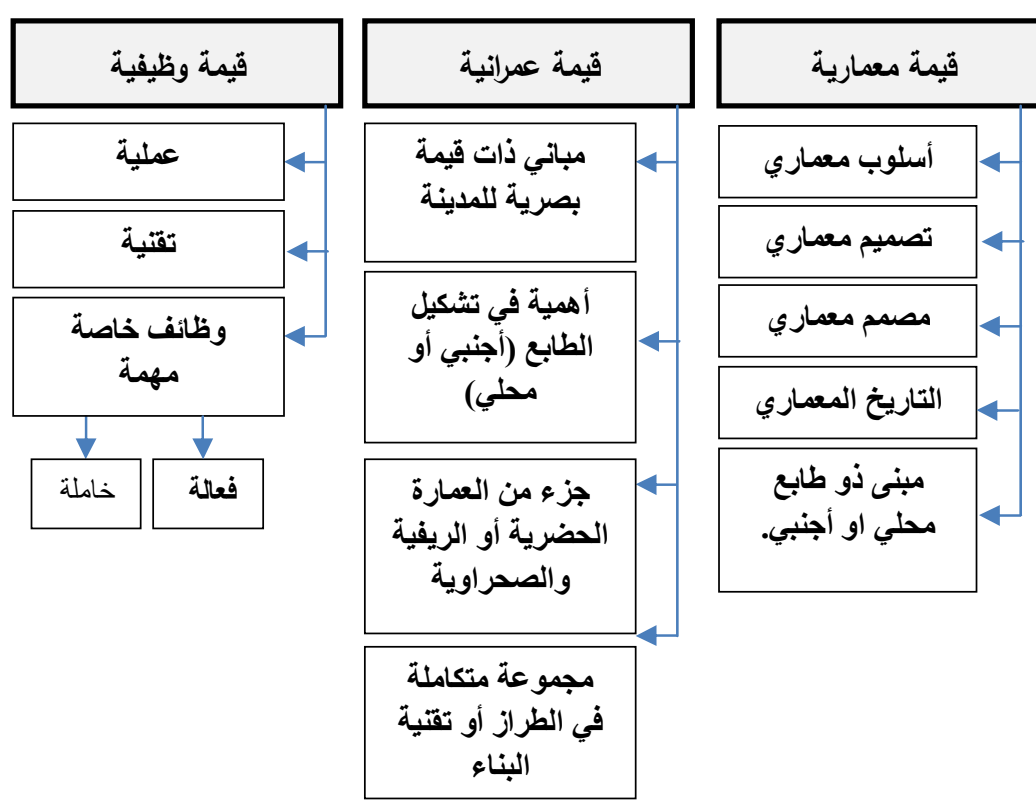

قيمة تاريخية (تسجيلية)
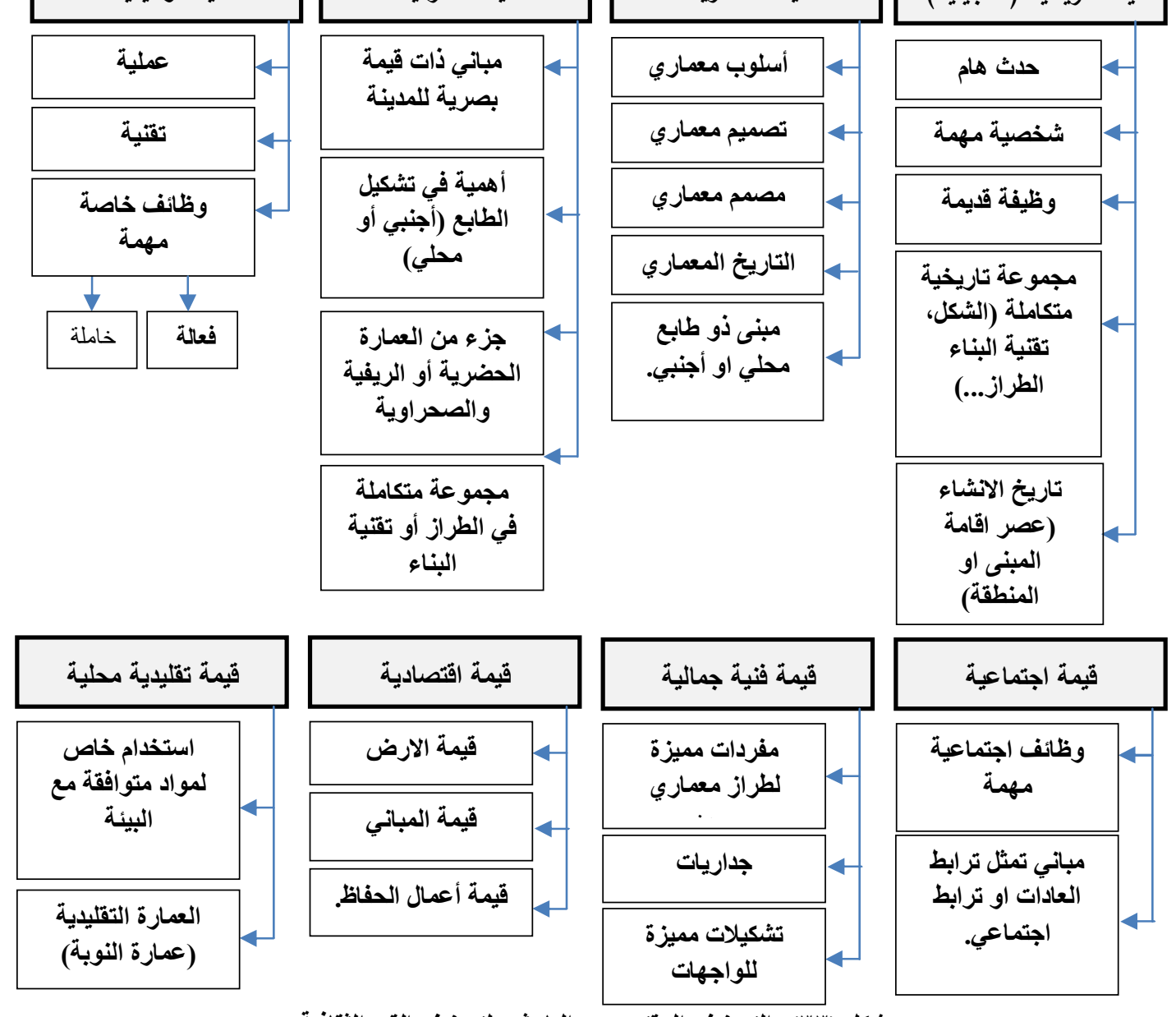

شكل (بr): التصنيف المقترح من الباحثين لتصنيف القيم الثقافية

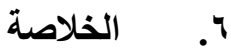 \\ 1-V}

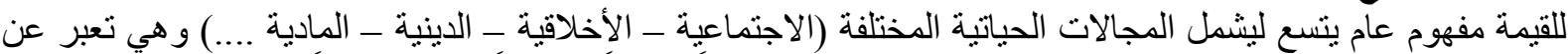

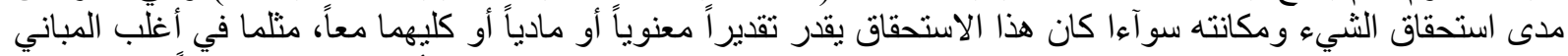

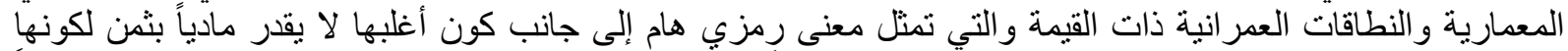

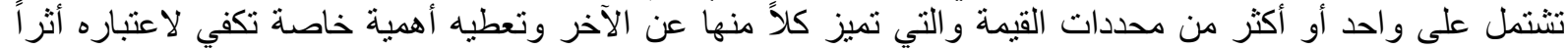

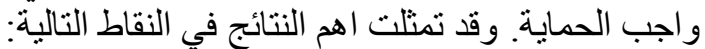
1 ـ المباني التراثية هي التي تكون الطابع القديم للمنطقة التاريخية إن هذا النسيج هو الإطار الثقافي المكمل لهذه الآثار

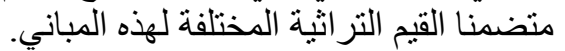

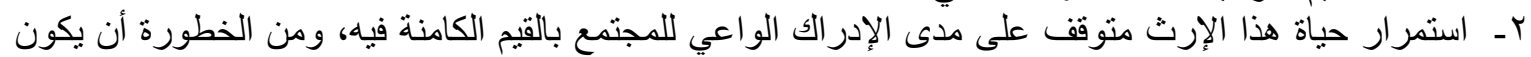

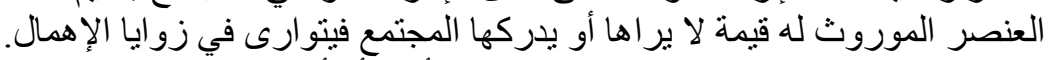

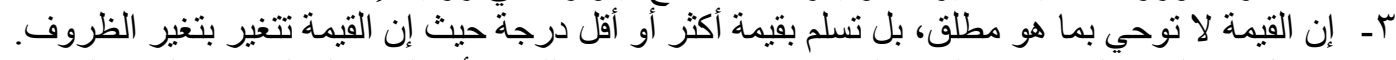

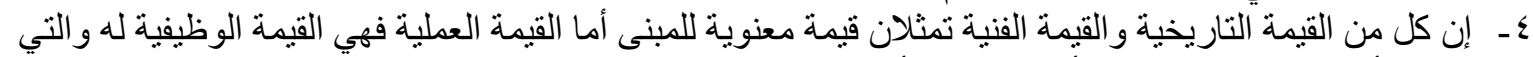

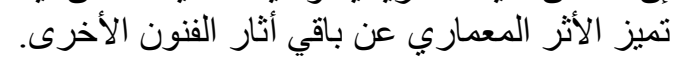

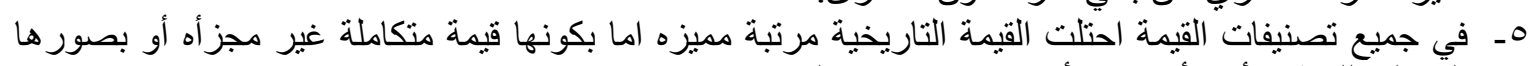
المختلفة للوظيفة أو الأشخاص أو كونها قيمة تسجيلية. 7- يمكن ان يجمع المبنى الواحد بين مجمو عة من القيم التراثية كالجمع بين القيمة التاريخية و الجمالية و المعمارية. 


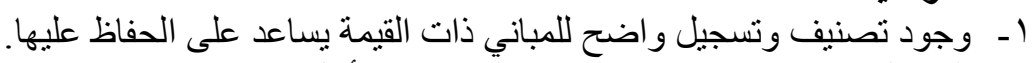

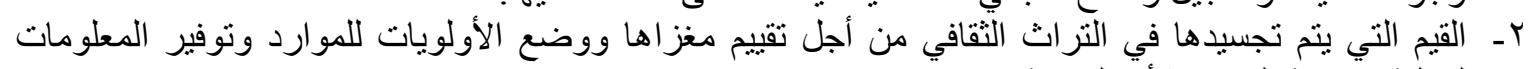
لعملية صناعة القرار بشأن الحماية.

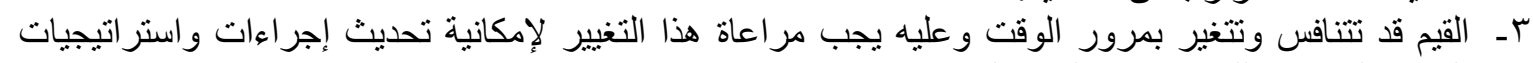
الحفاظ العمر اني للمباني ذات التئين القيمة التراثية. ع - يجب إجر اء مقارنات بين المباني ذات ذات النمط الو احد وفي نفس المنطقة. هذا سيجعل العلاقات أكثر وضوحاً وسوف

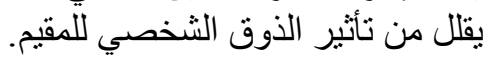

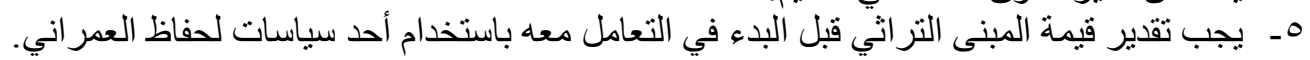

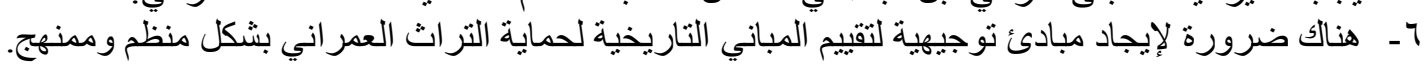

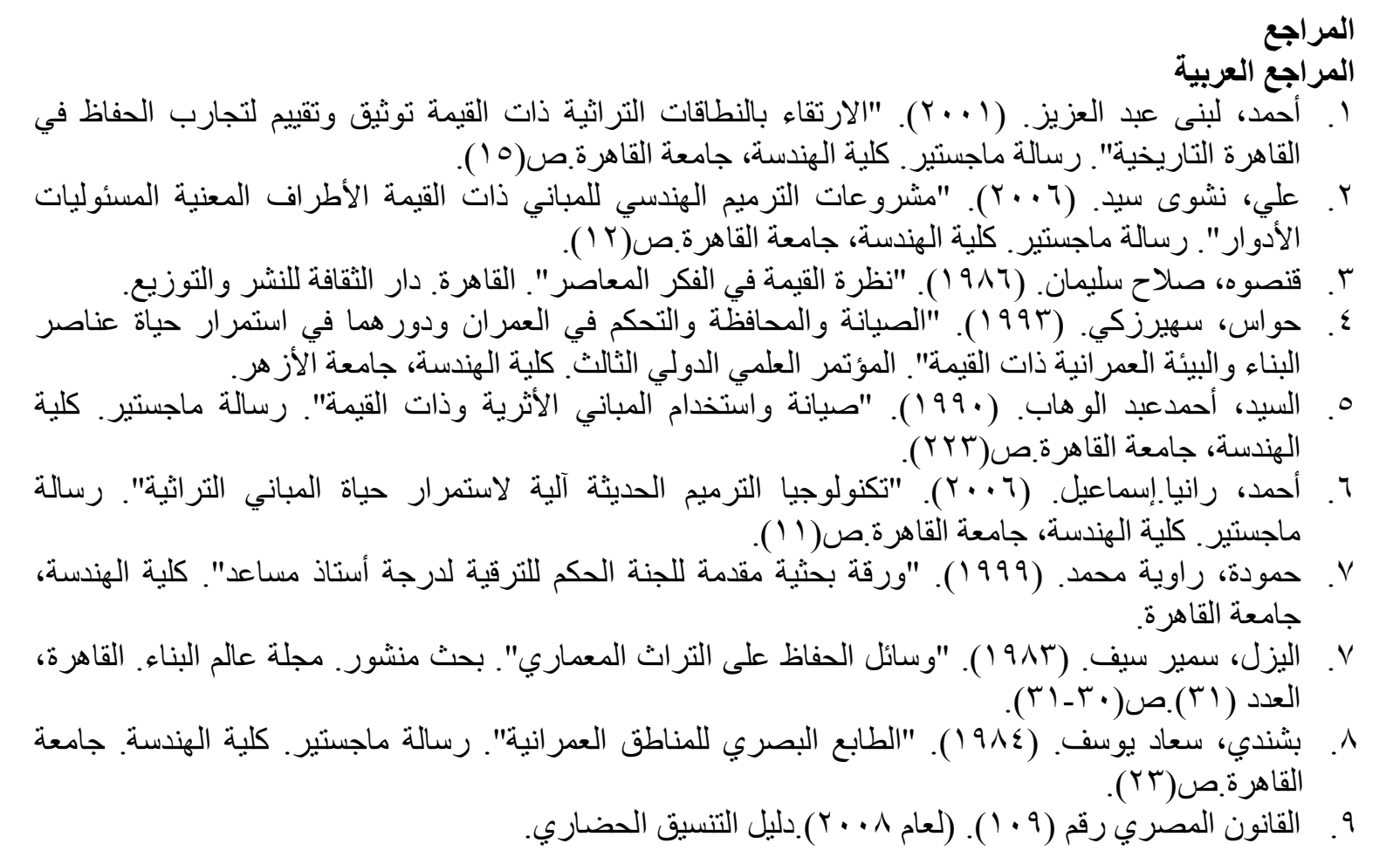

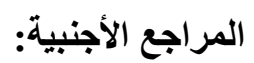

1. Worskett, Roy. J. (1970)."The Character of the Tows an Approach to Conservation", Arch. Press, London.

2. Munro, Thomas.G. (1963). "Evaluation in the Arts and other theories of Culture History", Cleveland Museum of Art. (Distributed by Harry M. Abrams, Inc.)

3. Daifuku Hiroshi.H. (1979). "The conversation of culture property". UNESCO.

4. Fielden, Bernard. M. (1994). "Conservation Historic Buildings" . Heinemann, London.

5. Strike، James. S. (1994). "Architecture in Conservation Managing Development at Historic Sites". Rout ledge. London. 